(6) OPEN ACCESS

\title{
Dual use of electronic nicotine delivery systems (ENDS) and smoked tobacco: a qualitative analysis
}

\author{
Lindsay Robertson, ${ }^{1}$ Janet Hoek, ${ }^{2}$ Mei-Ling Blank, ${ }^{2}$ Rosalina Richards, ${ }^{1}$ Pamela Ling, ${ }^{3}$ \\ Lucy Popova ${ }^{4}$
}

- Additional material is published online only. To view please visit the journal online (http://dx.doi.org/10.1136/ tobaccocontrol-2017-054070).

${ }^{1}$ Cancer Society Social and Behavioural Research Unit, Department of Preventive and Social Medicine, University of Otago, Dunedin, New Zealand 2Departments of Public Health and Marketing, University of Otago, Dunedin, New Zealand ${ }^{3}$ Center for Tobacco Control Research and Education, University of California San Francisco, San Francisco, California, USA

${ }^{4}$ School of Public Health, Georgia State University, Atlanta, Georgia, USA

\section{Correspondence to} Professor Janet Hoek, Departments of Public Health and Marketing, University of Otago, Dunedin 9054, New Zealand;

janet.hoek@otago.ac.nz

Received 28 September 2017 Revised 22 January 2018 Accepted 23 January 2018 Published Online First 1 February 2018
Check for updates

To cite: Robertson L, Hoek J, Blank M-L, et al. Tob Control 2019:28:13-19.

\section{ABSTRACT \\ Introduction Electronic nicotine delivery systems} (ENDS) arguably pose fewer health risks than smoking, yet many smokers adopt ENDS without fully relinquishing smoking. Known as 'dual use', this practice is widespread and compromises the health benefits that ENDS may offer. To date, few studies have explored how dual use practices arise and manifest.

Methods We conducted in-depth, semi-structured interviews with 20 current ENDS users from New Zealand who reported smoking tobacco at least once a month. We explored participants' smoking history, their recent and current smoking, trial, uptake and patterns of ENDS use, and future smoking and vaping intentions. We managed the data using NVivo V.11 and used a thematic analysis approach to interpret the transcripts.

Results Dual use practices among participants evolved in four ways. First, as an attempt to manage the 'inauthenticity' of vaping relative to smoking and to retain meaningful rituals. Second, as complex rationalisations that framed decreased tobacco use, rather than smoking cessation, as 'success'. Third, as a means of alleviating the financial burden smoking imposed and to circumvent smoke-free policies. Lastly, dual use reflected attempts to comply with social group norms and manage stigma.

Conclusions Dual use reflects both social and physical cues. It assisted participants to navigate smoking restrictions and allowed them to manage divergent norms. Policies that discourage smoking, particularly excise tax increases on smoked tobacco and smoke-free space restrictions, appear important in prompting ENDS use. Future research could explore whether these policies also help foster complete transition from smoking to exclusive ENDS use.

\section{INTRODUCTION}

Proponents of electronic nicotine delivery systems (ENDS) argue these devices could increase smoking cessation and reduce the widespread harms of smoked tobacco. ${ }^{12}$ Although evidence of these benefits remains contested, ${ }^{3}$ many smokers, motivated by rising tobacco costs, health concerns, smoking restrictions or increasingly stigmatised smoker identities, use ENDS to support quit attempts. ${ }^{4-7}$ Unlike nicotine replacement therapy or prescription cessation treatments, ENDS potentially mimic practices smokers value, by providing alternative hand-tomouth actions, retaining inhalation and supporting the creation of bespoke (custom-made) rituals..$^{7-11}$ Many ENDS users believe these devices will reduce the risks they face relative to smoking, help them navigate smoke-free restrictions and support their transition to becoming smoke-free. ${ }^{6} 1012-15$

While ENDS may pose fewer health risks than combustible tobacco products, many smokers fail to transition fully from smoking to vaping, despite initially intending to quit smoking completely. ${ }^{4}$ 16-20 For example, the UK Smoking Toolkit study reports that the majority of ENDS users continue to smoke, though the proportion of dual users (ie, people who smoke and vape) has declined from $86 \%$ in 2013 to $55 \%$ in $2017 . .^{21}$ Dual users continue to face serious health harms, even if they reduce their tobacco consumption. $^{22} 23$ Dual use may also reduce motivation to quit and the likelihood of successful cessation, ${ }^{162425}$ and compromises the population-level benefits that ENDS could deliver, ${ }^{17}{ }^{26-28}$ which depend on complete transition from smoking to vaping.

Research exploring dual use remains nascent, and recent calls for qualitative work probing dual use have not yet elicited a comprehensive response. ${ }^{29}$ To our knowledge, only three published qualitative studies have explored dual use patterns and experiences. The first described contexts in which current ENDS users were more likely to smoke (eg, after a meal, while out socialising, when consuming alcohol) or use their ENDS (eg, indoors, where smoking is not allowed, when cigarettes are not available). ${ }^{25}$ However, this study did not probe cognitive and social factors contributing to dual use, and more than a third of the participants had not smoked a cigarette in the past 30 days, raising doubts over whether the sample truly reflected current dual users. The second study focused primarily on physical differences and similarities between vaping and smoking, and considered social and identity factors in less detail. ${ }^{30}$ Analysis of an open-ended question used in a survey of UK smokers (of which 77\% had no intention to quit smoking) concluded that users typically saw ENDS as an additional nicotine consumption option, rather than as a replacement for cigarettes or a means of quitting. ${ }^{31}$ While the ability to use ENDS in more varied settings promoted uptake, the lack of satisfaction users experienced inhibited their transition to exclusive vaping. ${ }^{31}$ Despite the incomplete understanding of dual use, many countries are introducing more liberal access policies. ${ }^{32}$ Research exploring how dual-use practices develop and manifest is thus urgently needed to inform measures that promote full transition from smoking to vaping or complete cessation of all tobacco products. 


\section{METHODS}

\section{Sample and recruitment}

We recruited participants aged 18 and over from three urban areas in New Zealand-Dunedin, Wellington and Aucklandusing social media and community advertising. We also drew on whanaungatanga (kinship) and professional networks to purposefully recruit Māori (New Zealand's indigenous peoples) and Pacific participants. We classified participants as dual users if they reported currently smoking and vaping at least once a month. ${ }^{19}$ All participants received a $\$ N Z 40$ gift voucher to recognise costs incurred while participating in the research.

\section{Data collection}

Our semi-structured, in-depth interview guide contained specific discussion topics but retained flexibility in question wording and sequencing and allowed detailed probing. ${ }^{33}$ We explored participants' smoking histories and current smoking, then probed their trial, uptake and patterns of ENDS use, and smoking and vaping intentions (online supplementary file 1 contains the interview documents). Participants recorded their typical smoking and vaping patterns using time grids and provided information on their smoking and vaping behaviours, perceptions and demographics. All participants gave written informed consent before the interview commenced. We aimed to recruit a minimum of 20 participants, after which saturation (defined as no new idea elements in two consecutive interviews) was achieved and data collection stopped. Interviews lasted for approximately $60 \mathrm{~min}$ (range: 46-80 $\mathrm{min}$ ).

\section{Data analysis}

All interviews were recorded and subsequently transcribed verbatim. Using NVivo V.11, LR and JH coded three transcripts independently using a line-by-line open-coding approach, compared and refined initial categories, and developed codes. $\mathrm{JH}$ subsequently coded a further three interviews using these codes, and LR coded the remaining transcripts. We conferred regularly to review codes and ensure these captured new idea elements. Following coding, LR and JH independently reviewed three large themes to compare and check sub-theme classifications. LR and JH then reviewed all coded data, discussed emergent themes and agreed on subthemes.

\section{RESULTS}

\section{Participants' characteristics}

The sample comprised 7 women and 13 men (age range: 19-65 years). Twelve participants were New Zealand European, six were Māori and/or Pacific, and two were 'Other' ethnicity (ie, Indian, Middle-Eastern). Sixteen participants used ENDS daily, and most $(n=18)$ owned either a second-generation vape pen or a third-generation tank system (none used a cigalike (first-generation device)). Participants' vaping experience ranged from 1 month to 1 year. Fourteen participants reported smoking daily (cigarettes per day ranged from 3 to 30 ), with increased tobacco use when socialising. Fifteen participants reported having reduced their tobacco consumption since commencing vaping. Participants' nicotine dependence ranged from 0 (no dependence) to 5 (high dependence) on the Heaviness of Smoking Index, ${ }^{34}$ and 14 reported having made a quit attempt lasting at least 24 hours during the last 6 months. Table 1 outlines participants' characteristics and their smoking and vaping-related behaviours.

\section{Thematic analysis}

Participants' dual use practices had evolved in four ways. First, some participants who had begun vaping to quit smoking found
ENDS failed to simulate important smoking attributes and thus reported that ENDS lacked authenticity. Second, others who initially hoped to quit smoking subsequently reframed their goal from quitting to reducing smoking, which they believed brought similar benefits to 'quitting'. Third, participants who did not wish to quit smoking tobacco used ENDS to reduce the financial burden of smoking and circumvent smoke-free policies and norms. Lastly, some participants alternated between smoking and vaping to manage conflicting norms and social practices. Intermittent smokers vaped when socialising with other vapers, while daily smokers vaped to avoid affecting non-smokers; both smoked in settings where smoking was normative and vaping often highly stigmatised. These four themes were not mutually exclusive, but nonetheless represent distinct patterns in our transcripts.

\section{Inauthenticity}

Motivated by health concerns and the increasing financial cost of smoking, many participants had begun vaping intending to quit smoking tobacco completely. Yet, several participants found ENDS failed to meet their expectations and persisted with vaping because of over-riding anxieties about their health or to manage the cost of tobacco. Toby described his quest to replicate smoking experiences and the disappointment that followed:

...you can't just go from one to the other and expect it to be the same... When I first got my vape I was hoping that I wouldn't want cigarettes anymore but I still did. And that was sort of disappointing.

Despite failing to simulate smoking, vaping nonetheless helped participants to manage nicotine cravings; Angie explained: "it mentally blocks me and it tells me that I've had something", while Neal commented: "it kind of fought the feeling for wanting one." Yet, while ENDS controlled intense cravings, participants wanted more than a physiological distraction and hoped to continue experiencing other smoking attributes. For example, Paekia missed the sensations she ascribed to additional chemicals and saw vaping as no more than respiration:

...it gives you something, but not like a cigarette. You know, cigarettes [have] got that chemical, or a chemical in it that makes me feel like I'm getting something. Whereas a vapour just makes me feel like I'm inhaling, exhaling... I know that it's not the real deal.

Participants' perceptions of 'the real deal' varied; they wanted to replicate specific experiences, such as the nicotine rush, handfeel, throat-hit or taste. James oscillated between the nicotine sensation and hand-feel when explaining why he preferred smoking over vaping: "I think it might be the, the nicotine, it might be the nicotine or that action of having that [a cigarette] in my fingers perhaps." By contrast, Damian defined a 'proper' cigarette according to the 'throat-hit' it delivers: "Trying to make that transition between cigarettes to e-cigarettes, you don't get that throat-hit. You feel like you're not really having a proper cigarette." For others, the taste of combustible cigarettes defined tobacco's authenticity; Jane explained: “...sometimes you just want the real thing... It's a totally different taste, it's the taste, it's not the habit...it's not picking it up and holding it, it's the taste". Irrespective of the attributes participants' privileged, the metaphors they used-'proper', 'real', 'right' and 'actual'-illustrated their unsuccessful search to recreate smoking experiences.

The absence of these physical sensations undermined the relationships participants developed with ENDS and the psychological benefits they received. While Angie described cigarettes as 


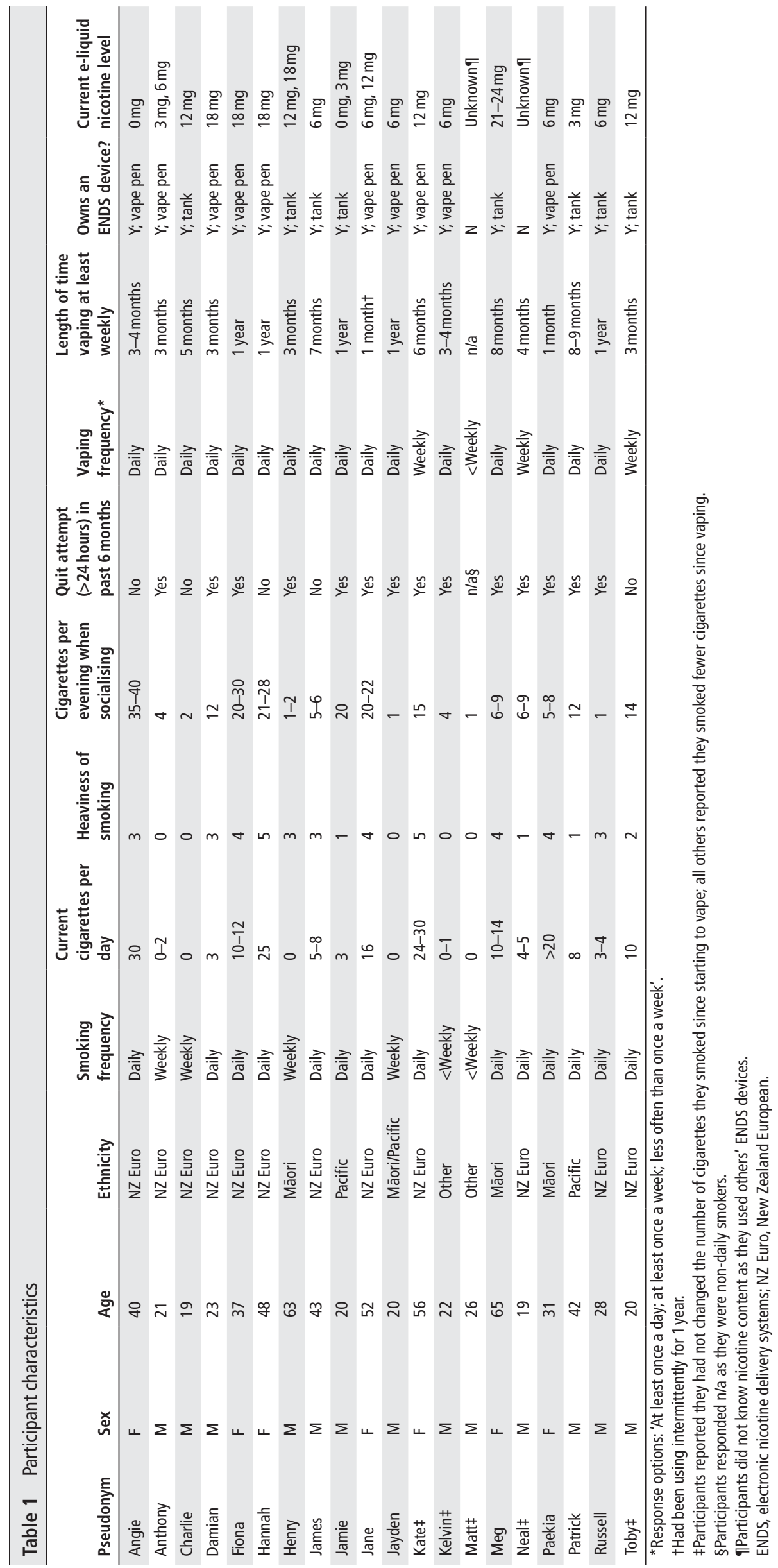


her 'best friend', Damian enjoyed tobacco's 'nostalgic feel' and Anthony felt smoking had a 'charm to it'; none viewed ENDS in these affectionate terms. Instead, several felt dissatisfied with how ENDS helped them regulate their emotions, particularly stress and anxiety. For example, Paekia's vapouriser did not offer the coping strategy she sought:

\begin{abstract}
...the reason why I wanted my cigarettes is because I've had so much going on. So like my course stuff... And I don't feel like my vape's [vapouriser's] doing it for me.
\end{abstract}

Participants also reported that ENDS did not replicate rituals they had developed around smoking; for example, intermittent smokers reported using smoking to excuse themselves from social situations. Relative to smoking, Anthony found his ENDS was 'not quite the same' in providing a socially sanctioned reason for being alone:

\begin{abstract}
...Just the whole idea of going out, kind of have some alone time... That's kind of probably one of the things I miss the most... It's not quite the same with a vape, but still kind of alright.
\end{abstract}

Vaping did not substitute for smoking in other ritualised practices, particularly those involving strongly paired physical sensations, such as coffee or alcohol consumption. Neal described missing the complementary attributes of smoking while drinking coffee:

\section{...like a coffee and a cigarette, it's kind of like a mixture of smooth and like rough. So the coffee's like nice and hot and the cigarette's like rough and burny... it's just not the same satisfaction or the same feeling that you would get from having a vape and a coffee.}

Nor did ENDS replicate the experience of smoking and drinking, especially when intoxicated. Charlie could not specify what he found 'really nice' about smoking and drinking, but knew he preferred a cigarette to his ENDS:

\begin{abstract}
...when you're drunk, there is something really nice about a cigarette. And so, if I had the choice between the cigarette and the e-cigarette... If I had two friends each handing me one, I would definitely go for the cigarette if I was drunk.
\end{abstract}

\section{Rationalising reduced smoking}

Despite initially hoping ENDS would help them quit, several participants had modified this goal and came to view reduced smoking as a successful outcome, as they believed they had ameliorated the risks they faced. Others used smoking to reward themselves for having temporarily abstained from smoking, and a few attributed healthful properties to vaping and thought these offset the risks of smoking tobacco.

Anthony explains how his goal shifted from quitting to reducing his tobacco use: "I did want to get it to quit. Not necessarily quit, just kind of lessen the need for it." Reducing smoking helped participants lower the risks they perceived and some saw decreased tobacco use as equivalent to quitting. James considered he had 'stopped smoking' (despite later reporting he smoked up to four cigarettes each day); knowing he had not made a 'clean break' did not allay his sense of achievement:

I'm so proud that I've stopped smoking like... I'm really pleased that I've given up cigarettes and I'm not smoking but part of me still feels as though, you know, I haven't cleanly made that break...

Satisfied with having substantially reduced his daily cigarette intake, Russell was 'happy' with his dual use; though he wished to quit smoking completely, he had no immediate intention to do so:
I'm sort of happy where it is at the moment because I was smoking like 40 a day so, you know, it's a hell of a lot cut down from what I was using, um, ideally I'd like to give up the smokes completely and just use the vape.

Some participants used smoking as a reward that they earned after a period of vaping; Kate showed high self-awareness and recognised how this rationalisation undermined her attempt to quit smoking:

... what I've done anyway, is, you know, using your e-cigarette and then thinking 'oh, I'll just have a cigarette 'cos I've been a good girl', well, you're not supposed to do that are ya?

Perceptions of ENDS as healthier than smoking also sanctioned smoking at a reduced level, as James's comments illustrate:

I know it's better than smoking so hence that is why I probably just have the occasional one [cigarette] you know, like maybe... I don't know, three a day is my probably the worst, I'd cap it at about four...

A few participants went further and framed ENDS not simply as less harmful, but as healthful. Matt considered vaping potentially 'medicinal', depending on the plant oils or 'essences' infused into the liquid. Neal drew on a simile of 'eating fruit', which he knew to be 'good for you', to describe vaping and justify lower-level smoking:

$$
\begin{aligned}
& \text {...it's like a clean cigarette and you almost feel it's like eating fruit } \\
& \text { that tastes good. Just like... it's good for you, so you kind of... } \\
& \text { feel good about eating it. And I think that's kind of the satisfaction } \\
& \text { you get from, like, an e-cigarette. }
\end{aligned}
$$

\section{Managing impositions}

Several participants had no intention of quitting tobacco but used vaping to offset inconveniences created by tobacco control measures. Paekia explained how ENDS' affordability relative to tobacco had motivated her to begin vaping:

Money was my motivation... There wasn't the fact that I wanted to quit, it was I didn't want to spend forty dollars every week on tailor-mades, rollies, cigarettes...

Nearly all participants cited the perceived acceptability of vaping indoors as highly appealing, and used ENDS to manage smoke-free restrictions:

Uh, it's good... [if] you can't be bothered walking outside, just [imitates vaping]... And then saves you the hassle of going outside. (Jamie)

Daily tobacco smokers reported frequent switching between cigarettes and ENDS throughout the day as they rationed their cigarettes and managed smoke-free areas. Patrick outlined how his practices had evolved:

I'll be vaping at the same times as I'll be having a cigarette... I'll be walking out to the smoking area and I'll be vaping.... sit down, have my one cigarette and then go back to work...In the morning, when I'm driving to work, I'll start—spark—this [tank] up first... then knowing I'm getting closer to work, then I'll have my cigarette.

Fiona's dual use practices facilitated uninterrupted nicotine consumption. She described smoking at the first available opportunity after leaving work, and switching to vaping at home to avoid the residual smell of smoke:

...the minute I leave work I have a cigarette... when I get to the bus stop, if I've got enough time I'll have another cigarette... I 
get home... probably about $3 \mathrm{pm}$-ish... and that's usually when I either am doing my housework or I sit and watch TV and that's when I do a lot of vaping cause I don't like smoking inside...so I'd probably do that till maybe $6 \mathrm{pm}$...

However, ENDS' potential for offsetting inconveniences of smoking had some shortcomings. ENDS devices required maintenance in a way cigarettes did not. While some participants enjoyed gaining technical mastery of their device, others found upkeep tedious, as Russell explains: “[it's] a real hassle going back and forward getting new coils." Technical difficulties also predisposed smoking, as Kelvin explains: "I'm finding more and more that I just want to smoke a cigarette because this just gets frustrating...”

\section{Adaptive social identities}

ENDS' novelty, exposure to friends' vaping and the attention ENDS generated, all stimulated trial and uptake of vaping among intermittent smokers, who enjoyed the convenience and camaraderie of vaping. Anthony and Charlie explained the satisfying 'social' and 'chill' connotations when vaping with friends:

...vaping is better, I suppose... it's kind of more social, you just hang around with your friends and vape inside. (Anthony)

It's more, sort of, chill. Like, you'll bring one out, or your friend will bring one out, and you'll just, sort of, pass it around or everyone will have a little try on it. (Charlie)

Yet vaping was not unambiguously positive; for some, it had a derogated status among their wider networks where social smoking remained normative. Kelvin described vaping in private with friends as they did not 'want to be seen doing it' in public, and Charlie outlined his own feelings of embarrassment:

I didn't find myself bringing it out to town... It was almost embarrassing, for some reason... I didn't want to be associated with that culture.... when I went out to town, I'd smoke a cigarette.

Daily smoking participants used vaping to manage perceptions of stigma and the unsettling feeling that their smoking caused discomfort to others. However, daily smokers did not experience the vaping-related stigma that intermittent smokers reported. Jane described how vaping enabled her to avoid 'irritating' others:

...it depends because probably the days I take my vape pen would be with the friends that don't smoke...so you just sit there and just puff and get that fix, that feeling you're needing, without it irritating everyone around you.

Toby also used vaping to avoid absenting himself to smoke:

...it's not like stigmatised. Like, if you're with people and they don't smoke, you don't want to smoke around them. But vaping isn't as bad because it doesn't have, like, the gross odour and vaping's sort of easier to do, you don't have to like go find somewhere away from people to vape.

Yet when in settings where smoking was normative, daily smokers smoked in preference to vaping; Fiona explained her practices:

...most of my friends smoke... and most of my family smoke so if I was out socially, I would be smoking...

\section{DISCUSSION}

We extend the scant qualitative literature on dual use of smoking and vaping by illustrating diverse dual use practices and the factors that shape their development. Several participants reported that ENDS lacked the physicality and perceived authenticity of smoking, ${ }^{10} 35$ to which they had developed strong attachments. Participants often felt nostalgic for the attributes and rituals they associated with smoking, and dual use reflected a yearning for the 'real' experience. Despite perceived inauthenticity, vaping persisted because of financial and health concerns about smoking. By sampling both intermittent and daily tobacco smokers, we illustrate how social norms influence smoking and vaping practices, and identify vaping-related stigma as a factor fostering dual use among intermittent or 'social' smokers.

Dual use reflected complex risk rationalisation strategies, where participants used vaping to reduce their smoking below a perceived harm threshold, which removed pressure to quit. By framing vaping as less harmful, even 'healthful', participants felt they offset the risks of smoking and justified their revised goal of reducing their tobacco use. Participants also used ENDS to respond to tobacco control measures, such as the cost of smoking and smoke-free area restrictions. Finally, dual use helped participants retain valued smoking rituals and social connections. ${ }^{9-1135}$ Depending on the context and audience, smoking and vaping may each generate social cachet and personal pleasure; dual use thus provides access to more diverse hedonic experiences. By fostering liminal identity positions, dual use allows smoker-vapers to switch nicotine delivery forms as they move between settings and social groups, and as normative practices change. ${ }^{3036-39}$

Our findings have three important implications. First, smokers looking to replicate the experience of smoking may be disappointed and should receive advice at point-of-sale that helps them set appropriate sensory expectations. As well as ensuring smokers understand ENDS will not simulate smoking, sales staff (often themselves experienced vapers) could assist smokers to calibrate the nicotine level in e-liquid with their current tobacco consumption, which may support smokers to persist with vaping exclusively.

Second, official health websites could provide the same advice to support appropriate nicotine substitution and avoid the risks of underdosing and overdosing. New and more specific guidelines could also promote full transition from smoking to vaping. Advice at the point-of-sale could dispel misperceptions that low-level smoking presents fewer risks, ${ }^{22}$ and recommend making a rapid transition to vaping. ${ }^{40}$ Cessation support workers and health practitioners could offer the same information while mass media health promotions and official health websites could further reinforce these messages.

Third, existing tobacco control policies provide important stimuli that prompt ENDS adoption and may also prove helpful in promoting exclusive vaping. For example, increasing the cost of smoked tobacco through excise taxation and creating more smoke-free areas could increase vaping's appeal relative to smoking and may have a role to play in fostering full transition as well as initial uptake. However, further research is required to assess how extending these policies affects vaping practices. Because not all dual users intend to quit but use vaping to manage smoke-free restrictions, new policy measures could reduce dual use opportunities, for example, by disallowing vaping in public indoor settings. ${ }^{41}$ Such a measure would challenge the perceived acceptability of indoor vaping, which fosters dual use; however, further work should assess potential effects on vaping uptake. ${ }^{42}$ Allowing vaping, but not smoking, in public outdoor settings offers a more cautious approach to promoting transition to vaping. ${ }^{41}$ 


\section{Study limitations and future research}

As with all qualitative research, the researchers' opinions and beliefs invariably influence the study process, from conceptualisation to interaction with participants, and data interpretation. ${ }^{43}$ However, team members' diverse views on ENDS' risks and benefits promoted rigorous debate and data analysis, while our inductive approach meant we identified themes from the data, rather than from a predetermined structure. Because our research questions were exploratory and probed how dual use arose and evolved, our findings need to be tested using a larger representative sample before we can generalise the themes presented.

Future research using population-based samples could address these questions and estimate how effectively ENDS deliver nicotine and whether specific vaping topographies (eg, puff intensity and duration) contribute to or reduce dual use. 'SmartENDS' that use bluetooth technology to passively record vaping patterns could support greater self-monitoring and may present opportunities to build the self-efficacy required for successful cessation. $^{44}$

Wider exploration of social factors, such as the vaping-related stigma that intermittent (and often younger) participants reported, may also offer important insights into how dual use arises and continues. Evidence that participants in a study of US college students also experienced vaping-related stigma highlights the need to probe how smokers negotiate complex new identity positions as vapers. ${ }^{45}$

In summary, our findings provide new insights into how dual use arises and continues, and we identify measures that could reduce sustained dual use. Further exploration of these measures is crucial if the potential population health benefits of ENDS are to be fully realised.

\section{What this paper adds}

- Several studies have found that many smokers who start using electronic nicotine delivery systems (ENDS) do not transition to exclusive vaping, but continue to smoke in addition to using ENDS ('dual use').

- Few studies have probed the factors that support and maintain dual use, or how dual users rationalise their continued smoking.

- Dual use reflects nostalgia for 'real' tobacco, allows negotiation of social contexts and helps smokers manage restrictions on smoking; dual users rationalise their practices by reframing reductions in smoked tobacco use as 'success' and equivalent to quitting.

- Providing ENDS purchasers with comprehensive point-of-sale advice could promote transition from smoking to exclusive vaping; policy measures such as excise tax increases and smoke-free area restrictions that prompt vaping uptake may also assist movement from smoking to vaping.

Acknowledgements We thank the research participants who provided the data reported on in this manuscript. We also thank Anna Latu and Kale Fruean who assisted with data collection, Stephanie Erick and Zoe Hawke who assisted with participant recruitment and Professors Phil Gendall and Richard Edwards for helpful feedback on earlier versions of the manuscript.

Contributors JAH conceptualised and designed the project, and obtained research funding. PL and LP provided feedback on the funding application. With $L R, M-L B$ and RR, JAH designed the research protocol. PL and LP provided feedback on the protocol. $L R, J A H$ and $M-L B$ conducted the fieldwork. LR led analysis of the transcripts, and she and JAH developed the manuscript. M-LB, RR, PL and LP provided feedback on draft versions of the manuscript. JAH and LR responded to the reviewers' comments. All authors have seen and approved the final version. LR and JAH are guarantors of the manuscript. LR is the lead author, and JAH is the senior author. Other authors are listed in order of contribution.

Funding This research was funded by the Health Research Council of New Zealand (grant 16/149).

Competing interests Although we do not consider it a competing interest, for the sake of full transparency we note that all authors have undertaken work for health sector agencies working in tobacco control.

\section{Patient consent Obtained.}

Ethics approval The University of Otago Human Ethics Committee (reference 16/132) approved the study.

Provenance and peer review Not commissioned; externally peer reviewed.

Open access This is an open access article distributed in accordance with the Creative Commons Attribution Non Commercial (CC BY-NC 4.0) license, which permits others to distribute, remix, adapt, build upon this work non-commercially, and license their derivative works on different terms, provided the original work is properly cited and the use is non-commercial. See: http://creativecommons.org/ licenses/by-nc/4.0/

(c) Article author(s) (or their employer(s) unless otherwise stated in the text of the article) 2019. All rights reserved. No commercial use is permitted unless otherwise expressly granted.

\section{REFERENCES}

1 Abrams DB. Promise and peril of e-cigarettes: can disruptive technology make cigarettes obsolete? JAMA 2014;311:135-6

2 Hajek P. Electronic cigarettes have a potential for huge public health benefit. BMC Med 2014;12:225.

3 El Dib R, Suzumura EA, Akl EA, et al. Electronic nicotine delivery systems and/or electronic non-nicotine delivery systems for tobacco smoking cessation or reduction: a systematic review and meta-analysis. BMJ Open 2017;7:e012680.

4 Dawkins L, Turner J, Roberts A, et al. 'Vaping' profiles and preferences: an online survey of electronic cigarette users. Addiction 2013;108:1115-25.

5 Dockrell M, Morrison R, Bauld L, et al. E-cigarettes: prevalence and attitudes in Great Britain. Nicotine Tob Res 2013;15:1737-44.

6 Barbeau AM, Burda J, Siegel M. Perceived efficacy of e-cigarettes versus nicotine replacement therapy among successful e-cigarette users: a qualitative approach. Addict Sci Clin Pract 2013:8:5.

7 Simmons VN, Quinn GP, Harrell PT, et al. E-cigarette use in adults: a qualitative study of users' perceptions and future use intentions. Addict Res Theory 2016;24:313-21.

8 Harrell PT, Simmons VN, Piñeiro B, et al. E-cigarettes and expectancies: why do some users keep smoking? Addiction 2015;110:1833-43.

9 Rooke C, Cunningham-Burley S, Amos A. Smokers' and ex-smokers' understanding of electronic cigarettes: a qualitative study. Tob Control 2016;25(e1):e60-6.

10 Hoek J, Thrul J, Ling P. Qualitative analysis of young adult ENDS users' expectations and experiences. BMJ Open 2017;7:e014990.

11 Hoek J, Ferguson S, Court E, et al. Qualitative exploration of young adult RYO smokers' practices. Tob Control 2016;26.

12 Majeed BA, Stanton CA, Dube SR, et al. Electronic cigarette use among current smokers: a pilot qualitative study. Health Behav Policy Rev 2016;3:590-6.

13 Kong G, Morean ME, Cavallo DA, et al. Reasons for electronic cigarette experimentation and discontinuation among adolescents and young adults. Nicotine Tob Res 2015:17:847-54.

14 Coleman BN, Johnson SE, Tessman GK, et al. "It's not smoke. It's not tar. It's not 4000 chemicals. Case closed": Exploring attitudes, beliefs, and perceived social norms of e-cigarette use among adult users. Drug Alcohol Depend 2016;159:80-5.

$15 \mathrm{Kim} \mathrm{H}$, Davis AH, Dohack JL, et al. E-cigarettes use behavior and experience of adults: qualitative research findings to inform e-cigarette use measure development. Nicotine Tob Res 2017;19:190-6.

16 Manzoli L, Flacco ME, Ferrante M, et al. Cohort study of electronic cigarette use: effectiveness and safety at 24 months. Tob Control 2017;26:284-92.

17 Goniewicz ML, Leigh NJ, Gawron M, et al. Dual use of electronic and tobacco cigarettes among adolescents: a cross-sectional study in Poland. Int J Public Health 2016;61:189-97.

18 Wills TA, Knight R, Williams RJ, et al. Risk factors for exclusive e-cigarette use and dual e-cigarette use and tobacco use in adolescents. Pediatrics 2015;135:e43-

19 Rath JM, Villanti AC, Abrams DB, et al. Patterns of tobacco use and dual use in US young adults: the missing link between youth prevention and adult cessation. J Environ Public Health 2012;2012:1-9.

20 Etter JF, Bullen C. Electronic cigarette: users profile, utilization, satisfaction and perceived efficacy. Addiction 2011;106:2017-28.

21 West R, Brown J. Smoking in England: latest statistics. 2017.

22 Schane RE, Ling PM, Glantz SA. Health effects of light and intermittent smoking: a review. Circulation 2010;121:1518-22. 
23 Begh R, Lindson-Hawley N, Aveyard P. Does reduced smoking if you can't stop make any difference? BMC Med 2015;13:257.

24 Kalkhoran S, Glantz SA. E-cigarettes and smoking cessation in real-world and clinical settings: a systematic review and meta-analysis. Lancet Respir Med 2016;4:116-28.

25 Pokhrel P, Herzog TA, Muranaka N, et al. Contexts of cigarette and e-cigarette use among dual users: a qualitative study. BMC Public Health 2015;15:859.

26 Zhu SH, Zhuang YL, Wong S, et al. E-cigarette use and associated changes in population smoking cessation: evidence from US current population surveys. BMJ 2017;358:j3262.

27 Reid JL, Rynard VL, Czoli CD, et al. Who is using e-cigarettes in Canada? Nationally representative data on the prevalence of e-cigarette use among Canadians. Prev Med 2015;81:180-3.

28 Brown J, Beard E, Michie S, et al, E-cigarette use \& smoking cessation in England. DEBRA symposium. 2017.

29 Wills TA, Sargent JD. Do E -cigarettes reduce smoking? Preventive Medicine 2017; 100:285-6.

30 Vandrevala T, Coyle A, Walker V, et al. 'A good method of quitting smoking' or 'just an alternative to smoking'? Comparative evaluations of e-cigarette and traditional cigarette usage by dual users. Health Psychol Open 2017:4:205510291668464.

31 McKeganey N, Dickson T. Why don't more smokers switch to using E-cigarettes: the views of confirmed smokers. Int J Environ Res Public Health 2017:14:647.

32 New Zealand Government. Nicotine e-cigarettes to become legal. 2017.

33 Patton MQ. Qualitative research and evaluation methods. Third ed. Thousand Oaks, CA: Sage Publications, 2002.

34 Borland R, Yong HH, O'Connor RJ, et al. The reliability and predictive validity of the heaviness of smoking index and its two components: findings from the International Tobacco Control Four Country study. Nicotine Tob Res 2010;12(suppl_1):S45-50.
35 Wigginton B, Morphett K, Gartner C. Is it the nicotine? Australian smokers' accounts of nicotine addiction. Addict Res Theory 2017;25:293-301.

36 Thompson L, Pearce J, Barnett JR, et al. smoking islands and responsible subjects. Area 2007;39:508-17.

$37 \mathrm{McCool}$ J, Hoek J, Edwards R, et al. Crossing the smoking divide for young adults: expressions of stigma and identity among smokers and nonsmokers. Nicotine Tob Res 2013;15:552-6.

38 Blue S, Shove E, Carmona C, et al. Theories of practice and public health: understanding (un)healthy practices. Crit Public Health 2016;26:36-50.

39 Keane H, Weier M, Fraser D, et al. 'Anytime, anywhere': vaping as social practice. Crit Public Health 2017;27:465-76.

40 Biener L, Hargraves JL. A longitudinal study of electronic cigarette use among a population-based sample of adult smokers: association with smoking cessation and motivation to quit. Nicotine Tob Res 2015;17:127-33.

41 Wilson N, Hoek J, Thomson G, et al. Should e-cigarette use be included in indoor smoking bans? Bull World Health Organ 2017;95:540-1.

42 Bauld L, McNeill A, Hajek P, et al. E-cigarette use in public places: striking the right balance. Tob Control 2017;26(e1):e5-6.

43 Kuper A, Reeves S, Levinson W. Qualitative research: an introduction to reading and appraising qualitative research. BMJ 2008;337:404-7.

44 Blank M-L, Hoek J, Richards M, et al, "Smart" e-cigarettes and smartphones: real-time data collection among smokers attempting to quit using an e-cigarette. Oceania Tobacco Control Conference, Hobart, Australia, 2017.

45 Case K, Crook B, Lazard A, et al. Formative research to identify perceptions of e-cigarettes in college students: Implications for future health communication campaigns. J Am Coll Health 2016;64:380-9. 